\title{
Step-up Therapy for Children with Uncontrolled Asthma While Receiving Inhaled Corticosteroids
}

\author{
Robert F. Lemanske Jr., M.D., David T. Mauger, Ph.D., Christine A. Sorkness, Pharm.D., \\ Daniel J. Jackson, M.D., Susan J. Boehmer, M.S., Fernando D. Martinez, M.D., Robert C. \\ Strunk, M.D., Stanley J. Szefler, M.D., Robert S. Zeiger, M.D., Ph.D., Leonard B. Bacharier, \\ M.D., Ronina A. Covar, M.D., Theresa W. Guilbert, M.D., Gary Larsen, M.D., Wayne J. Morgan, \\ M.D., Mark H. Moss, M.D., Joseph D. Spahn, M.D., Lynn M. Taussig, M.D., and for the \\ Childhood Asthma Research and Education (CARE) Network of the National Heart, Lung, and \\ Blood Institute \\ University of Wisconsin School of Medicine and Public Health, Madison (R.F.L., C.A.S., D.J.J., \\ T.W.G., M.H.M.); the Department of Public Health Sciences, Pennsylvania State University, \\ Hershey (D.T.M., S.J.B.); Arizona Respiratory Center, University of Arizona, Tucson (F.D.M., \\ W.J.M.); the Department of Pediatrics, Washington University, St. Louis (R.C.S., L.B.B.); the \\ Department of Pediatrics, National Jewish Health and University of Colorado Denver School of \\ Medicine, Denver (S.J.S., R.A.C., G.L., J.D.S., L.M.T.); and the Department of Pediatrics, University \\ of California-San Diego, and the Department of Allergy, Kaiser Permanente - both in San Diego \\ (R.S.Z.)
}

\section{Abstract}

BACKGROUND—For children who have uncontrolled asthma despite the use of low-dose inhaled corticosteroids (ICS), evidence to guide step-up therapy is lacking.

\begin{abstract}
METHODS-We randomly assigned 182 children (6 to 17 years of age), who had uncontrolled asthma while receiving $100 \mu \mathrm{g}$ of fluticasone twice daily, to receive each of three blinded step-up therapies in random order for 16 weeks: $250 \mu \mathrm{g}$ of fluticasone twice daily (ICS step-up), $100 \mu \mathrm{g}$ of fluticasone plus $50 \mu \mathrm{g}$ of a long-acting beta-agonist twice daily (LABA step-up), or $100 \mu \mathrm{g}$ of fluticasone twice daily plus 5 or $10 \mathrm{mg}$ of a leukotriene-receptor antagonist daily (LTRA step-up). We used a triple-crossover design and a composite of three outcomes (exacerbations, asthma-control days, and the forced expiratory volume in 1 second) to determine whether the frequency of a differential response to the step-up regimens was more than $25 \%$.
\end{abstract}

RESULTS-A differential response occurred in 161 of 165 patients who were evaluated $(\mathrm{P}<0.001)$. The response to LABA step-up therapy was most likely to be the best response, as compared with responses to LTRA step-up (relative probability, 1.6; 95\% confidence interval [CI], 1.1 to $2.3 ; \mathrm{P}=$ 0.004 ) and ICS step-up (relative probability, $1.7 ; 95 \% \mathrm{CI}, 1.2$ to $2.4 ; \mathrm{P}=0.002$ ). Higher scores on the Asthma Control Test before randomization (indicating better control at baseline) predicted a better response to LABA step-up $(\mathrm{P}=0.009)$. White race predicted a better response to LABA stepup, whereas black patients were least likely to have a best response to LTRA step-up $(\mathrm{P}=0.005)$.

CONCLUSIONS-Nearly all the children had a differential response to each step-up therapy. LABA step-up was significantly more likely to provide the best response than either ICS or LTRA step-up. However, many children had a best response to ICS or LTRA step-up therapy, highlighting

Copyright $@ 2010$ Massachusetts Medical Society.

Address reprint requests to Dr. Lemanske at the University of Wisconsin Hospital, 600 Highland Ave., K4-916, Madison, WI 53792, or at rfl@medicine.wisc.edu .

No other potential conflict of interest relevant to this article was reported. 
the need to regularly monitor and appropriately adjust each child's asthma therapy.

(ClinicalTrials.gov number, NCT00395304.)

Uncontrolled asthma occurs in many children who receive treatment with low-dose inhaled corticosteroids. In the Pediatric Asthma Controller Trial (PACT), 1 administration of $100 \mu \mathrm{g}$ of fluticasone twice daily was the most effective therapy, but uncontrolled asthma occurred in more than $50 \%$ of the children, and $39 \%$ of the children had at least one asthma exacerbation that was treated with oral corticosteroids during a 48-week period. The few data that are available to guide practitioners about how to treat children whose asthma is poorly controlled while they are receiving low-dose inhaled corticosteroids $2^{-} 8$ are inconsistent. The discrepancies may be related to the choice of a single primary outcome measure (e.g., peak expiratory flow); to differences in the duration of treatment, eligibility criteria, or choice of comparison groups; and to evaluation of the responses of groups rather than of individual patients. Evidence from comparison studies is needed to establish which step-up therapy is best and whether there are phenotypic or genotypic characteristics that can be used to predict whether a child will have a better response to one particular step-up treatment than to another.

In this study, called the Best Add-on Therapy Giving Effective Responses (BADGER) trial, we assessed the frequency of differential responses to three blinded step-up treatments in children who had uncontrolled asthma while receiving low-dose inhaled corticosteroids. We used a three-way crossover design with a composite of outcomes (asthma exacerbations, asthma-control days, and the forced expiratory volume in 1 second $\left[\mathrm{FEV}_{1}\right]$ ), which allowed us to determine the probability that a given treatment would produce the best response. We also determined whether specific baseline characteristics could be used to predict the response to step-up treatment.

\section{METHODS \\ STUDY PATIENTS}

From March 2007 through July 2008, we recruited patients, 6 to 17 years of age, at Childhood Asthma Research and Education (CARE) Network centers. Inclusion criteria were mild-tomoderate asthma diagnosed by a physician on the basis of criteria recommended by the National Asthma Education and Prevention Program, ${ }^{9}$ an ability to perform reproducible spirometry, an $\mathrm{FEV}_{1}$ of at least $60 \%$ before bronchodilation, and an increase in the $\mathrm{FEV}_{1}$ of at least $12 \%$ (bronchodilator reversibility) or a methacholine provocation concentration causing a $20 \%$ fall $\left(\mathrm{PC}_{20}\right)$ in the $\mathrm{FEV}_{1}$ of $12.5 \mathrm{mg}$ per milliliter or less.

Each center's institutional review board approved the study, and parents or guardians provided written informed consent. In addition, children under 7 years of age provided oral assent, and older children provided written assent.

\section{STUDY PROTOCOL}

The protocol that we used to guide study procedures is provided in the Supplementary Appendix, available with the full text of this article at NEJM.org. Briefly, all patients were enrolled in a run-in period of 2 to 8 weeks to determine whether their asthma was poorly controlled while they were receiving $100 \mu \mathrm{g}$ of fluticasone twice daily. The run-in period could be shortened by up to 1 week for safety reasons in case of a sudden worsening in symptoms. Patients or their parents or guardians recorded symptoms and peak-flow determinations in a diary each day. A patient became eligible for randomization after the documentation of uncontrolled asthma, which was defined as the occurrence of at least one of the following for more than 2 days per week on average during a 2-week period: diary-reported symptoms (coughing rated as moderate or severe or wheezing rated as mild, moderate, or severe), rescue 
use of an inhaled bronchodilator with two or more puffs per day, or peak flows under $80 \%$ of the predetermined reference value.

Patients then entered a randomized, doubleblind, three-treatment, three-period crossover trial for a total of 48 weeks. During each 16-week period, patients received $250 \mu \mathrm{g}$ of fluticasone (Flovent Diskus, GlaxoSmithKline) twice daily (inhaled-corticosteroid [ICS] step-up therapy), $100 \mu \mathrm{g}$ of fluticasone plus $50 \mu \mathrm{g}$ of the long-acting beta-agonist salmeterol (Advair Diskus, GlaxoSmithKline) twice daily (LABA step-up ther-apy), or $100 \mu \mathrm{g}$ of fluticasone twice daily plus 5 or $10 \mathrm{mg}$ of the leukotriene-receptor antagonist montelukast (Singulair, Merck) daily (LTRA step-up therapy). The drug assignments were masked with the use of placebo tablets and dummy disk devices that discharged powder without the active drug. The initial 4 weeks of the last two 16-week periods were considered to be the active washout from the previous period.

Patients received an open-label metered-dose inhaler of albuterol (Ventolin HFA, GlaxoSmithKline), prednisone, and a customized written action plan to guide use. A standardized course of prednisone treatment was initiated for an asthma exacerbation if predetermined clinical criteria were met. Asthma characteristics were assessed by means of CARE Network procedures that have been described previously. ${ }^{10}$ Patients were evaluated at 4-week intervals (Fig. 1). Measurements of the fraction of exhaled nitric oxide and methacholine bronchoprovocation were performed as described previously. $1 \mathrm{We}$ administered the validated Pediatric Asthma Quality of Life Questionnaire11 to assess patients' impairment from asthma, with scores ranging from 1 to 7 and higher scores indicating less impairment (with a minimally important difference [MID] of 0.5); the Asthma Control Test12, 13 (for children 12 years of age or older), with scores ranging from 5 to 25 and higher scores indicating greater control (with an MID of 3.0); and the Childhood Asthma Control Test14 (for children between the ages of 4 and 11 years), with scores ranging from 0 to 27 and higher scores indicating greater control (with an undefined MID).

\section{OUTCOME MEASURES}

The primary outcome was the differential response to each of the three step-up therapies on the basis of fixed threshold criteria for the following three asthma-control measures: the need for treatment with oral prednisone for acute asthma exacerbations, the number of asthmacontrol days, and the $\mathrm{FEV}_{1}$. One treatment period was ranked as better than another if the total amount of prednisone received during the period was atleast $180 \mathrm{mg}$ less, if the number of annualized asthma-control days during the final 12 weeks of the period was increased by at least 31 days, or if the $\mathrm{FEV}_{1}$ at the end of the period was at least $5 \%$ higher. If the prednisone threshold was met, then we ignored the number of asthma-control days and the $\mathrm{FEV}_{1}$. If the threshold for asthma-control days was met, then we ignored the $\mathrm{FEV}_{1}$. Otherwise, the order of response was determined by the $\mathrm{FEV}_{1}$. If none of the thresholds were met, then we gave the same rank to each treatment period and the patient was considered not to have had a differential response. A patient was considered to have had a differential response if at least one treatment period was ranked as better than another.

Oral prednisone was administered according to a protocol that has been described previously.

${ }^{1}$ An asthma-control day, as documented in each patient's diary, was a day during which there was no use of albuterol rescue (excluding the use of albuterol as preexercise treatment), no use of a nonstudy asthma medication, no daytime or nighttime asthma symptoms, no unscheduled visit to a health care provider for asthma, and no peak expiratory flow of less than $80 \%$ of the predetermined reference value. We calculated annualized asthma-control days as 365 times the proportion of asthma-control days during the final 12 weeks of the period, which were adjusted for seasonal differences. 


\section{STUDY OVERSIGHT}

Fluticasone and salmeterol were donated by the manufacturer, GlaxoSmithKline, which also donated the albuterol that was provided to patients; montelukast was donated by Merck. The manufacturers had no role in the study design, the accrual or analyses of data, or the preparation of the manuscript. The authors vouch for the completeness and accuracy of the data.

\section{STATISTICAL ANALYSIS}

The primary analysis involved two stages: a onesided exact test for binomial proportions to test the null hypothesis that the percentage of patients with a differential response (i.e., those for whom the three treatments were not ranked the same) would be less than or equal to $25 \%$ at the 0.01 significance level, and if there was a significant result in stage one, a rank-ordered logistic regression ${ }^{15}$ to test whether four prespecified baseline covariates would predict distinct patterns of differential responses. Each covariate was tested at the 0.01 significance level so that the overall type I error rate for the primary analysis was 0.05 . Secondary analyses tested the predictive values of other baseline covariates at the 0.05 significance level.

The number of patients who were enrolled in the study provided adequate power for both stages of the primary analysis. A total sample of 180 patients, with an assumed $15 \%$ loss to followup, would provide a power of $90 \%$ for the first stage if the true percentage of patients with a differential response was at least $40 \%$, and would provide the same power for each of the four prespecified covariates in the second stage if the covariate predicted a change of more than $15 \%$ in the probability of a best response for each treatment.

We constructed rank-ordered logit models and calculated bootstrap-based 95\% confidence intervals with the use of Stata software, version 11. Classification analysis was used to examine the goodness of fit of the model. Model results are presented for dichotomized covariates to simplify interpretation of continuous predictors. Sensitivity analyses also modeled them as ordinal covariates (quartiles) and continuous covariates to confirm that dichotomization did not mask relationships. Sensitivity analyses assessed the possible influence of treatment carryover effects by testing for period effect and treatment-by-period interaction effect in the regression models.

\section{RESULTS \\ STUDY PATIENTS}

Of the 480 patients who were enrolled, 298 were excluded during the run-in phase. Thus, 182 patients underwent randomization, of whom 157 completed all three study periods (Fig. 1). A total of 165 patients completed two study periods, permitting assessment of the differential response. Table 1 presents baseline demographic and physiological data, stratified according to age group. (Baseline data stratified according to the study-group assignment during period 1 are available in Table E1 in the Supplementary Appendix.) Patients completed 90\% of the study visits and provided sufficient data in the symptom diaries to determine control status on $96 \%$ of study days. The rate of adherence to study medication was $84 \%$ for study tablets (as measured by an electronic monitor in the bottle cap) and $87 \%$ for study inhalers (as measured by a disk counter).

\section{DIFFERENTIAL RESPONSE TO THE THREE STEP-UP THERAPIES}

A differential response occurred in 161 of 165 patients (98\%), a proportion that was significantly greater than the one-sided null hypothesis of $25 \%(\mathrm{P}<0.001)$. The percentage of asthma-control days differed according to season in all study groups, ranging from $71 \%$ in winter months to $79 \%$ in summer months. Asthma exacerbations were most frequent during winter months. The average $\mathrm{FEV}_{1}$ (measured as a percentage of the predicted value) varied by 
less than $1 \%$ across seasons. Seasonal variation affected only $12 \%$ of patients for whom the number of annualized asthma-control days determined the differential response. Sensitivity analysis indicated that seasonal differences in the $\mathrm{FEV}_{1}$ had no significant effect on the results, whereas seasonal differences in exacerbations had a small effect that was neither statistically nor qualitatively significant.

Subsequent analyses were performed to characterize the pattern of differential response. In pairwise comparisons, the proportion of patients who had a better response to LABA step-up was higher than the proportion with a better response to LTRA step-up (52\% vs. 34\%, P= 0.02 ), and the proportion with a better response to LABA step-up was higher than the proportion with a better response to ICS step-up ( $54 \%$ vs. $32 \%, \mathrm{P}=0.004)$, whereas the responses to LTRA and ICS step-up therapies were similar (Fig. 2A). The primary outcome of the trial, a three-way comparison of step-up therapy with the use of rank-ordered logistic regression, predicted that the response to LABA step-up was significantly more likely to be the best response, as compared with the response to LTRA step-up (relative probability, 1.6; 95\% confidence interval $[\mathrm{CI}], 1.1$ to $2.3 ; \mathrm{P}=0.004$ ) and the response to ICS step-up (relative probability, $1.7 ; 95 \% \mathrm{CI}, 1.2$ to $2.4 ; \mathrm{P}=0.002$ ) (Fig. 2B).

\section{PRIMARY ANALYSIS OF PREDICTORS OF DIFFERENTIAL RESPONSE}

The ability of the four preselected factors to predict patterns of differential response is shown in Figure 3. Patterns of differential response were not predicted by methacholine $\mathrm{PC}_{20}$ values, either dichotomized at the median baseline value $(\mathrm{P}=0.2)$ or examined as a continuous covariate $(\mathrm{P}=0.37)$ (Fig. 3A), or by the fraction of exhaled nitric oxide, either dichotomized at the median baseline value $(\mathrm{P}=0.7)$ or examined as a continuous covariate $(\mathrm{P}=0.52)$ (Fig. 3B). Baseline scores on the Asthma Control Test and the Childhood Asthma Control Test that were dichotomized at validated numerical scores indicative of acceptable control $(>19)$ or unacceptable control $(\leq 19)$ significantly predicted patterns of differential response $(\mathrm{P}=0.009)$, with higher scores predicting a greater probability that the best response would be to LABA step-up (Fig. 3C). Finally, the genotype at position 16 of the $\beta_{2}$-adrenergic receptor did not predict patterns of response $(\mathrm{P}=0.49)$ (Fig. 3D).

\section{SECONDARY ANALYSIS OF PREDICTORS OF DIFFERENTIAL RESPONSE}

We evaluated other factors post hoc, including demographic and physiological characteristics and asthma history, as predictors of a differential re-sponse. Figure 4 shows the clinical relevance of three of these factors: race or ethnic group, the presence or absence of eczema, and age. Race or ethnic group significantly predicted patterns of differential response $(\mathrm{P}=$ 0.005 without correction for multiple testing), with Hispanic and non-Hispanic white patients most likely to have a best response to LABA step-up and least likely to have a best response to ICS step-up, and black patients equally likely to have a best response to LABA or ICS stepup therapy and less likely to have a best response to LTRA step-up (Fig. 4A). There were no differences in the patterns of differential response according to age, whether age was examined as a dichotomous covariate ( 5 to 11 years or $\geq 12$ years) or as a continuous covariate (Fig. 4B). Finally, patients who did not have eczema were most likely to have a best response to LABA step-up $(\mathrm{P}=0.006$ without correction for multiple testing) (Fig. 4C).

Of the seven other factors examined post hoc to predict patterns of differential response, none were significant as either dichotomous or continuous covariates. Factors that were evaluated were sex $(P=0.10)$, presence or absence of perennial allergen sensitization $(P=0.16)$, baseline pre-bronchodilator $\mathrm{FEV}_{1}$ of $90 \%$ or less or more than $90 \%(\mathrm{P}=0.70)$, bronchodilator reversibility ( $>10 \%$ vs. $\leq 10 \%)(\mathrm{P}=0.08)$, previous use or nonuse of a controller medication $(\mathrm{P}=0.90)$, the baseline number of asthma-control days $(\mathrm{P}=0.08)$, and the number of recent asthma exacerbations $(0$ vs. $\geq 1)(\mathrm{P}=0.90)$. 
The rank-ordered logit model that included only the significant predictors correctly classified the observed ranks $68 \%$ of the time. The interaction between period and treatment according to period was not significant, indicating that it was unlikely that effects of treatment carryover could have biased the results.

\section{ADVERSE EVENTS}

There were seven serious adverse events, one during the run-in period (asthma exacerbation) and six during the treatment phase (five of which required hospitalization): two each in the LABA step-up group (asthma exacerbation and appendicitis), the LTRA step-up group (asthma exacerbation and need for tonsillectomy-adenoidectomy), and the ICS step-up group (asthma exacerbation and behavioral issues not requiring hospitalization). Thrush that was classified as probably related to the study drug was reported in one patient during treatment with LABA step-up and in two patients during treatment with ICS step-up. A total of 25 treatment failures occurred: 3 hospitalizations for asthma-related symptoms (1 during each study treatment) and 22 involving the need for a second prednisone burst ( 3 during treatment with LABA, 8 during treatment with ICS, and 11 during treatment with LTRA). A total of 120 prednisone bursts were prescribed for asthma exacerbations (30 during treatment with LABA, 47 during treatment with ICS, and 43 during treatment with LTRA) (for details, see Table E2 in the Supplementary Appendix).

\section{DISCUSSION}

In this trial, we examined step-up strategies for children who had uncontrolled asthma while receiving low-dose inhaled corticosteroids. When the three step-up treatments were compared, 98\% of the children had a differential response, with the best response during LABA step-up occurring significantly more frequently than during LTRA or ICS step-up. The direction of this best response should not have been biased by the entry criteria, because $20 \%$ of the children qualified for the study on the basis of bronchodilator reversibility alone, 58\% qualified on the basis of methacholine hyperresponsiveness alone, and 22\% met both criteria. Moreover, $\mathrm{FEV}_{1}$ values after bronchodilation were not significant predictors of the response to LABA step-up, providing further evidence against this bias.

Our findings suggest that there is a ceiling effect of low-dose inhaled corticosteroids in many, though not all, children. Our data show that to achieve improvements in asthma control, the addition of a different class of medication is often required. Furthermore, although LABA stepup therapy was most likely to provide the best response, some children had a best response to one of the other step-up therapies. For the most part, baseline characteristics did not predict the therapy most likely to be best for an individual patient. We found that baseline scores on the Asthma Control Test and the Childhood Asthma Control Test indicating better control were associated with a higher probability that LABA would be the best add-on therapy. The predictive value of other characteristics may have been limited by run-in treatment - for example, baseline values for the fraction of exhaled nitric oxide and $\mathrm{PC}_{20}$ were obtained after at least 2 weeks of low-dose inhaled corticosteroids, unlike the predictive value of these measures in children who had not received inhaled corticosteroids, as reported in PACT. ${ }^{16}$

In secondary analyses, findings regarding self-reported race or ethnic group were noteworthy. Black patients were equally likely to have a best response to LABA or ICS step-up therapy and were least likely to have a best response to LTRA step-up. In contrast, in white subjects, LABA step-up was clearly most likely to provide the best response. A number of studies have reported a differential response to asthma therapy on the basis of race or ethnic group. ${ }^{17,18}$ These differences appear to primarily involve responsiveness to beta-agonists, which may be related to genetic variations ${ }^{19}$ and gene-by-gene interactions. ${ }^{20}$ 
The observed best overall performance of LABA therapy should be weighed against the potential increased risks of such therapy that are cited in the Food and Drug Administration's approved labeling.21 Our study was not designed or powered to evaluate the long-term safety of LABA in children. Although we found that LABA step-up therapy was associated with the smallest number of treatment failures and exacerbations, the between-group differences were not significant, and we emphasize that the duration of our trial and the size of our sample preclude statements regarding long-term risks. Clinicians who prescribe LABAs (never to be used as monothera-py22,23) in combination with inhaled corticosteroids should continue to evaluate risk-benefit ratios.

Despite step-up in daily therapy, 120 exacerbations requiring the use of oral corticosteroids occurred during the treatment periods. Day-today asthma control, as reflected by the number of asthma-control days, was quite good with all three step-up therapies. However, none of the step-up therapies completely prevented asthma exacerbations. These findings underscore the need for new therapies aimed at preventing exacerbations.

In summary, our study showed a clinically significant differential response in nearly all the children and identified several characteristics of the children that predicted the direction of differential responses, including race or ethnic group and two readily available clinical attributes: asthma control, as indicated by the score on the Asthma Control Test, and the presence or absence of eczema. More expensive and labor-intensive measures of physiological factors (e.g., methacholine $\mathrm{PC}_{20}$ ) and biomarkers (e.g., the fraction of exhaled nitric oxide) did not have predictive value. Although LABA step-up was significantly more likely to provide the best response than either ICS or LTRA step-up, many children had a best response to ICS or LTRA step-up, highlighting the need to regularly monitor and appropriately adjust each child's asthma therapy within this level of care before further step-up.

\section{Supplementary Material}

Refer to Web version on PubMed Central for supplementary material.

\section{Acknowledgments}

Supported by grants from the National Heart, Lung, and Blood Institute (HL064307, HL064288, HL064295, HL064287, HL064305, and HL064313), the National Institute of Allergy and Infectious Diseases (T32AI007635), and the Clinical Translational Science Award program of the National Center for Research Resources (UL1-RR025011 [Wisconsin], UL1-RR025780 [Colorado], and UL1-RR024992 [St. Louis]). This study was performed in part by the General Clinical Research Centers at Washington University School of Medicine (M01-RR00036), National Jewish Health (M01-RR00051), and the University of Wisconsin (M01-RR03186).

Dr. Lemanske reports receiving consulting fees from MAP Pharmaceuticals, Gray Consulting, Smith Research, Quintiles, Scienomics, R.C. Horowitz, Merck, AstraZeneca, and Novartis, lecture fees from Medicus Group, Merck, and AstraZeneca, and grant support from Pharmaxis and Genentech; Dr. Mauger, lecture fees from Roche; Dr. Sorkness, consulting fees from Glaxo-SmithKline, Schering-Plough, and AstraZeneca and grant support from Schering-Plough, Pharmaxis, and Sandoz; Dr. Jackson, grant support from Pharmaxis and GlaxoSmithKline; Dr. Martinez, consulting fees from Merck, MedImmune, and GlaxoSmithKline, lecture fees from Genentech and Merck, and grant support from AstraZeneca, GlaxoSmithKline, Eli Lilly, Diamyd, Inspire, Gilead, Boehringer Ingelheim, Nestle, Bayer, MedImmune, Mpex Pharmaceuticals, Pharmaxis, and Respironics; Dr. Szefler, consulting fees from Boehringer Ingelheim, Genentech, Glaxo-SmithKline, Merck, Novartis, and Schering-Plough, lecture fees from Merck, and research grants from GlaxoSmithKline and Abbott; Dr. Zeiger, consulting fees from Aerocrine, AstraZeneca, DynaVac, Genentech, GlaxoSmithKline, MedImmune, Merck, Novartis, and Schering-Plough, lecture fees from AstraZeneca, and grant support from Genentech, Novartis, Merck, GlaxoSmithKline, and Aerocrine; Dr. Bacharier, consulting fees from Aerocrine, GlaxoSmithKline, Genentech, Novartis, Merck, and Schering-Plough and lecture fees from Aerocrine, AstraZeneca, Genentech, GlaxoSmithKline, Merck, and Schering-Plough; Dr.Covar, consulting fees from Merck and a research grant from Abbott; Dr. Guilbert, consulting fees from GlaxoSmithKline, Merck, AstraZeneca, Genetech, Novartis, and MAP Pharmaceuticals and lecture fees from GlaxoSmithKline, Merck, PeerPoint Medical Education Institute, AstraZeneca, Antidote CME programs, Schering-Plough, and Novartis; Dr. Larsen, consulting fees from Genentech; Dr. Morgan, consulting fees from Genen-tech, Vertex Pharmaceuticals, and 
Novartis, lecture fees from Phadia, and grant support from Novartis; and Dr. Spahn, consulting and lecture fees from GlaxoSmithKline.

\section{REFERENCES}

1. Sorkness CA, Lemanske RF Jr, Mauger DT, et al. Long-term comparison of 3 controller regimens for mild-moderate persistent childhood asthma: the Pediatric Asthma Controller Trial. J Allergy Clin Immunol 2007;119:64-72. [PubMed: 17140647]

2. Verberne AA, Frost C, Duiverman EJ, Grol MH, Kerrebijn KF. Addition of salmeterol versus doubling the dose of beclomethasone in children with asthma. Am J Respir Crit Care Med 1998;158:213-219. [PubMed: 9655732]

3. Bensch G, Berger WE, Blokhin BM, et al. One-year efficacy and safety of inhaled formoterol dry powder in children with persistent asthma. Ann Allergy Asthma Immunol 2002;89:180-190. [PubMed: 12197575]

4. de Blic J, Ogorodova L, Klink R, et al. Salmeterol/fluticasone propionate vs. double dose fluticasone propionate on lung function and asthma control in children. Pediatr Allergy Immunol 2009;20:763771. [PubMed: 19239660]

5. Gappa M, Zachgo W, von Berg A, Kamin W, Stern-Sträter C, Steinkamp G. Add-on salmeterol compared to double dose fluticasone in pediatric asthma: a double-blind randomized trial (VIAPAED). Pediatr Pulmonol 2009;44:1132-1142. [PubMed: 19824054]

6. Tal A, Simon G, Vermeulen JH, et al. Budesonide/formoterol in a single inhaler versus inhaled corticosteroids alone in the treatment of asthma. Pediatr Pulmonol 2002;34:342-350. [PubMed: 12357478]

7. Ni Chroinin M, Lasserson TJ, Greenstone I, Ducharme FM. Addition of long-acting beta-agonists to inhaled corticosteroids for chronic asthma in children. Cochrane Database Syst Rev 2009;3 CD007949.

8. Simons FE, Villa JR, Lee BW, et al. Montelukast added to budesonide in children with persistent asthma: a randomized, double-blind, crossover study. J Pediatr 2001;138:694-698. [PubMed: 11343045]

9. National Asthma Education Prevention Program. Expert Panel Report 3 (EPR-3): guidelines for the diagnosis and management of asthma: summary report 2007. J Allergy Clin Immunol 2007;120 Suppl:S94-S138. [PubMed: 17983880]

10. Strunk RC, Szefler SJ, Phillips BR, et al. Relationship of exhaled nitric oxide to clinical and inflammatory markers of persistent asthma in children. J Allergy Clin Immunol 2003;112:883-892. [PubMed: 14610474]

11. Juniper EF, Guyatt GH, Feeny DH, Ferrie PJ, Griffith LE, Townsend M. Measuring quality of life in children with asthma. Qual Life Res 1996;5:35-46. [PubMed: 8901365]

12. Nathan RA, Sorkness CA, Kosinski M, et al. Development of the asthma control test: a survey for assessing asthma control. J Allergy Clin Immunol 2004;113:59-65. [PubMed: 14713908]

13. Schatz M, Kosinski M, Yarlas AS, Hanlon J, Watson ME, Jhingran P. The minimally important difference of the Asthma Control Test. J Allergy Clin Immunol 2009;124:719-723. [PubMed: 19767070]

14. Liu AH, Zeiger R, Sorkness C, et al. Development and cross-sectional validation of the Childhood Asthma Control Test. J Allergy Clin Immunol 2007;119:817-825. [PubMed: 17353040]

15. Marden, JI. Analyzing and modeling rank data. London: Chapman \& Hall; 1995.

16. Knuffman JE, Sorkness CA, Leman-ske RF Jr, et al. et al. Phenotypic predictors of long-term response to inhaled corticosteroid and leukotriene modifier therapies in pediatric asthma. J Allergy Clin Immunol 2009;123:411-416. [PubMed: 19121860]

17. Naqvi M, Thyne S, Choudhry S, et al. Ethnic-specific differences in bronchodilator responsiveness among African Americans, Puerto Ricans, and Mexicans with asthma. J Asthma 2007;44:639-648. [PubMed: 17943575]

18. Naqvi M, Tcheurekdjian H, DeBoard JA, et al. Inhaled corticosteroids and augmented bronchodilator responsiveness in Latino and African American asthmatic patients. Ann Allergy Asthma Immunol 2008;100:551-557. [PubMed: 18592818] 
19. Moore PE, Ryckman KK, Williams SM, Patel N, Summar ML, Sheller JR. Genetic variants of GSNOR and ADRB2 influence response to albuterol in African-American children with severe asthma. Pediatr Pulmonol 2009;44:649-654. [PubMed: 19514054]

20. Corvol H, De Giacomo A, Eng C, et al. Genetic ancestry modifies pharmacogenetic gene-gene interaction for asthma. Pharmacogenet Genomics 2009;19:489-496. [PubMed: 19503017]

21. Kramer JM. Balancing the benefits and risks of inhaled long-acting beta-agonists - the influence of values. N Engl J Med 2009;360:1592-1595. [PubMed: 19369665]

22. Lazarus SC, Boushey HA, Fahy JV, et al. Long-acting beta2-agonist monotherapy vs continued therapy with inhaled corticosteroids in patients with persistent asthma: a randomized controlled trial. JAMA 2001;285:2583-2593. [PubMed: 11368732]

23. Lemanske RF Jr, Sorkness CA, Mauger EA, et al. Inhaled corticosteroid reduction and elimination in patients with persistent asthma receiving salmeterol: a randomized controlled trial. JAMA 2001;285:2594-2603. [PubMed: 11368733] 


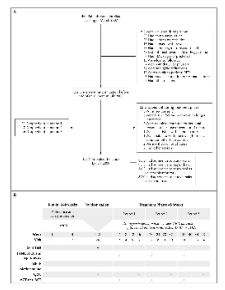

Figure 1. Enrollment and Outcomes and Schedule of Evaluations

Panel A shows the number of patients who enrolled in the study, underwent randomization, and completed the study. $\mathrm{FEV}_{1}$ denotes forced expiratory volume in 1 second, $\mathrm{PC}_{20}$ provocation concentration of methacholine causing a $20 \%$ fall in $\mathrm{FEV}_{1}$, and PFT pulmonaryfunction test. Panel B shows the schedule for various tests and procedures and the administration of the Pediatric Asthma Quality of Life Questionnaire to assess asthma impairment at specific study visits. Visit 2 a was the randomization visit. ACT denotes Asthma Control Test, BR4P bronchodilator response to four puffs of albuterol, c-ACT Childhood Asthma Control Test, FEN fraction of exhaled nitric oxide, FO forced oscillometry, and QOL quality-of-life questionnaire. 


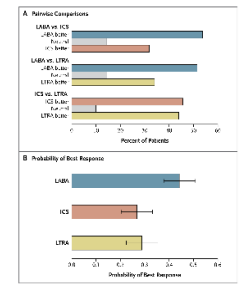

Figure 2. Pairwise Comparison of Three Step-up Therapies and the Overall Probability of Best Response

Panel A shows pairwise comparisons of the three step-up therapies. The proportion of patients with a best response to a long-acting beta-agonist (LABA) step-up was higher than the proportion with a best response to a leuko triene-receptor antagonist (LTRA) step-up (52\% vs. $34 \%, \mathrm{P}=0.02)$ or an inhaled corticosteroid (ICS) step-up ( $54 \%$ vs. $32 \%, \mathrm{P}=0.004)$; the bestresponse results for LTRA step-up were similar to those for an ICS step-up. Panel B shows the pattern of differential response according to the probability that the best response to a treatment occurred during the period in which that treatment was received; LABA step-up was most likely to provide the best response. Covariate-adjusted estimates were obtained from rankordered logistic-regression models; I bars indicate bootstrap-based $95 \%$ confidence intervals. 


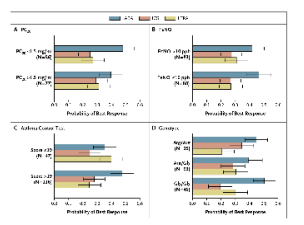

Figure 3. Primary Predictors of a Differential Response to Step-up Therapy

The four factors that are shown were preselected as potential predictors of a differential response among patients receiving step-up therapy with a long-acting beta-agonist (LABA), an inhaled corticosteroid (ICS), or a leukotriene-receptor antagonist (LTRA). Three of these factors did not identify distinct patterns of differential response: the meth choline provocation concentration causing a $20 \%$ fall $\left(\mathrm{PC}_{20}\right)$ in the forced expiratory volume in 1 second (Panel A), the fraction of exhaled nitric oxide ( $\mathrm{F}_{\mathrm{ENO}}$ ) (Panel B), and the genotype for the $\beta_{2}$-adrenergic receptor (Panel D). T fourth factor - the baseline score on the Asthma Control Test (for children 12 years of age or older, measured on scale of 5 to 25) or the Childhood Asthma Control Test (for children between the ages of 4 and 11 years, measured on a scale from 0 to 27 , with higher scores on both tests indicating greater control) — did identify distinct patterns of differential response $(\mathrm{P}=0.009)$, with scores of more than 19 predicting an increased likelihood of a best response to LABA step-up therapy (Panel C). Estimates were obtained from rank-ordered logistic-regression models; I bars indicate bootstrap-based $95 \%$ confidence intervals. 


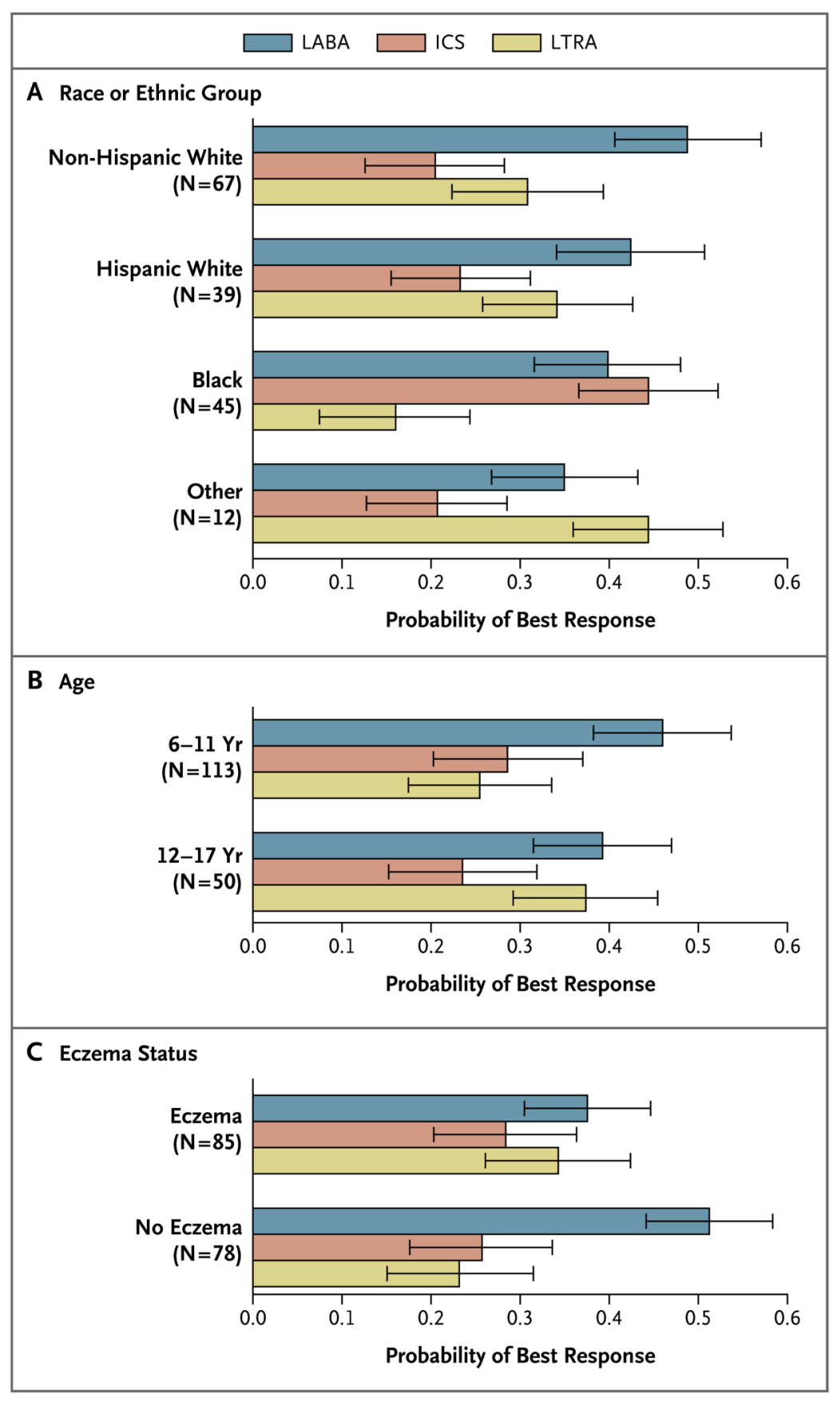

Figure 4. Secondary Predictors of a Differential Response to Step-up Therapy

Shown is the probability of a best response to step-up therapy with a long-acting beta-agonist (LABA), an inhaled corticosteroid (ICS), or a leuko-triene-receptor antagonist (LTRA), according to race or ethnic group, age, and the presence or absence of eczema, factors that were evaluated in post hoc analysis. Race or ethnic group was a significant predictor $(\mathrm{P}=0.005)$, with Hispanic and non-Hispanic white patients most likely to have a best response to LABA step-up therapy and black patients equally likely to have a best response to LABA or ICS stepup and least likely to have a best response to LTRA step-up (Panel A). Age was not a significant predictor of a differential response (Panel B). Patients who did not have eczema were most likely to have a best response to LABA step-up therapy $(\mathrm{P}=0.006)$ (Panel $\mathrm{C})$. Estimates were 
obtained from rank-ordered logistic-regression models; I bars indicate bootstrap-based $95 \%$ confidence intervals. P values have not been corrected for multiple testing. 
Table 1

Baseline Characteristics of the Patients. ${ }^{*}$

\begin{tabular}{|c|c|c|}
\hline \multirow[t]{2}{*}{ Characteristic } & \multicolumn{2}{|c|}{ Age Group } \\
\hline & 6-11 Yr $(\mathrm{N}=126)$ & $12-17$ Yr $(N=56)$ \\
\hline Age $-\mathrm{yr}$ & $9.1 \pm 1.5$ & $14.7 \pm 1.7$ \\
\hline Male sex — no. $(\%)$ & $83(66)$ & $36(64)$ \\
\hline \multicolumn{3}{|l|}{ Race or ethnic group - no. $(\%)^{\dagger}$} \\
\hline Hispanic or Latino & $38(30)$ & $22(39)$ \\
\hline Non-Hispanic white & $54(43)$ & $20(36)$ \\
\hline Black & $37(29)$ & $12(21)$ \\
\hline Hispanic white & $28(22)$ & $15(27)$ \\
\hline Other & $7(6)$ & $9(16)$ \\
\hline Height $-\mathrm{cm}$ & $134.3 \pm 10.8$ & $164.2 \pm 11.0$ \\
\hline Weight — kg & $36.1 \pm 12.7$ & $63.4 \pm 17.2$ \\
\hline Body-mass index & $19.6 \pm 4.5$ & $23.3 \pm 4.8$ \\
\hline Age at asthma diagnosis $-\mathrm{yr}$ & $3.3 \pm 2.2$ & $4.7 \pm 4.1$ \\
\hline Age at onset of asthma symptoms $-\mathrm{yr}$ & $2.4 \pm 2.2$ & $3.8 \pm 3.6$ \\
\hline \multicolumn{3}{|l|}{ Family history of asthma — no. (\%) } \\
\hline Father & $33(26)$ & $17(30)$ \\
\hline Mother & $44(35)$ & $12(21)$ \\
\hline Eczema - no. $(\%)$ & $69(55)$ & $24(43)$ \\
\hline \multicolumn{3}{|l|}{ Positive aeroallergen skin test } \\
\hline Any — no. & $2.6 \pm 2.1$ & $3.7 \pm 2.4$ \\
\hline$\geq 1-$ no./total no. $(\%)$. & $95 / 122(78)$ & $48 / 55(87)$ \\
\hline \multicolumn{3}{|l|}{ Positive perennial skin test } \\
\hline Any — no. & $1.4 \pm 1.3$ & $2.0 \pm 1.4$ \\
\hline$\geq 1-$ no./total no. $(\%)$ & $82 / 122(67)$ & $48 / 55(87)$ \\
\hline Serum IgE $-\mathrm{IU} / \mathrm{ml}$ & $493.4 \pm 690.5$ & $530.5 \pm 589.0$ \\
\hline Blood eosinophils - \% & $5.1 \pm 3.7$ & $5.3 \pm 4.8$ \\
\hline \multicolumn{3}{|l|}{ Eligibility classification - no. $(\%)^{\frac{\xi}{\xi}}$} \\
\hline Step-up & $35(28)$ & $14(25)$ \\
\hline Step-neutral & $16(13)$ & $11(20)$ \\
\hline Step-down & $75(60)$ & $31(55)$ \\
\hline \multicolumn{3}{|l|}{ Medication use in previous year - no. $(\%)$} \\
\hline Inhaled or nebulized corticosteroid & $82(65)$ & $39(70)$ \\
\hline Leukotriene modifier & $46(37)$ & $14(25)$ \\
\hline Salmeterol & $5(4)$ & $5(9)$ \\
\hline Theophylline & 0 & 0 \\
\hline Cromolyn or nedocromil & 0 & $1(2)$ \\
\hline Salmeterol plus fluticasone, or budesonide plus formoterol & $41(33)$ & $18(32)$ \\
\hline
\end{tabular}




\begin{tabular}{|c|c|c|}
\hline \multirow[t]{2}{*}{ Characteristic } & \multicolumn{2}{|c|}{ Age Group } \\
\hline & 6-11 Yr $(\mathrm{N}=126)$ & $12-17$ Yr $(N=56)$ \\
\hline Prednisone $(\geq 1$ courses $)$ & $56(44)$ & $25(45)$ \\
\hline Prebronchodilator $\mathrm{FEV}_{1}-\%$ of predicted value & $98.5 \pm 13.1$ & $95.0 \pm 14.8$ \\
\hline Prebronchodilator $\mathrm{FEV}_{1}: \mathrm{FVC}$ ratio & $81.6 \pm 7.1$ & $78.2 \pm 7.1$ \\
\hline Bronchodilator response, 4 puffs $-\%$ & $11.2 \pm 11.2$ & $13.5 \pm 10.2$ \\
\hline Asthma-control days during worst 2 weeks of run-in period - $\%$ & $30 \pm 21$ & $36 \pm 23$ \\
\hline Score on Asthma Control Test or Childhood Asthma Control Test ${ }^{\S}$ & $20.5 \pm 3.8$ & $19.8 \pm 3.4$ \\
\hline \multicolumn{3}{|l|}{ Exhaled nitric oxide - ppb } \\
\hline Median & 8.5 & 17.7 \\
\hline Interquartile range & $5.8-13.1$ & $11.4-26.2$ \\
\hline \multicolumn{3}{|l|}{ Methacholine $\mathrm{PC}_{20}-\mathrm{mg} / \mathrm{ml}$} \\
\hline Median & 1.24 & 2.06 \\
\hline Interquartile range & $0.56-3.83$ & $0.70-5.44$ \\
\hline \multicolumn{3}{|l|}{$\beta_{2}$-adrenergic-receptor genotype - no. $(\%)^{q /}$} \\
\hline $\operatorname{Arg} / \operatorname{Arg}$ & $19(15)$ & $10(18)$ \\
\hline Arg/Gly & $71(57)$ & $31(55)$ \\
\hline Gly/Gly & $34(27)$ & $15(27)$ \\
\hline
\end{tabular}

* Plus-minus values are means \pm SD. The body-mass index is the weight in kilograms divided by the square of the height in meters. Percentages may not total 100 because of rounding. $\mathrm{FEV}_{1}$ denotes forced expiratory volume in 1 second, FVC forced vital capacity, and $\mathrm{PC}_{20}$ provocation concentration causing a $20 \%$ fall in FEV 1 .

${ }^{\dagger}$ Race or ethnic group was self-reported.

*The run-in medication was $100 \mu \mathrm{g}$ of fluticasone twice daily. The category for patients who were taking an equivalent dose of an inhaled corticosteroid at baseline was termed "step-neutral," the category for those who were not receiving an inhaled corticosteroid or were taking a lower dose at baseline was termed "step-up," and the category for those who were taking a higher dose of an inhaled corticosteroid or combination therapy at baseline was termed "step-down."

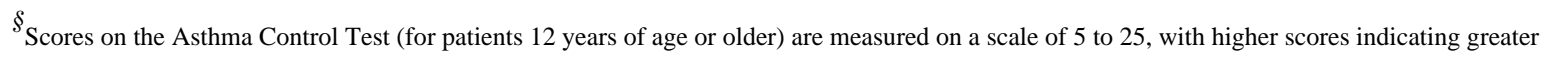
control. Scores on the Childhood Asthma Control Test (for children between the ages of 4 and 11 years) are measured on a scale from 0 to 27 , with higher scores indicating greater control.

II Data were missing for two patients between the ages of 6 and 11 years. 